\title{
Substantial reductions in ambient PAHs pollution and lives saved as a co-benefit of effective long-term PM2.5 pollution controls
}

DOI:

10.1016/j.envint.2018.03.002

\section{Document Version}

Accepted author manuscript

Link to publication record in Manchester Research Explorer

Citation for published version (APA):

Kong, S., Yan, Q., Zheng, H., Liu, H., Wang, W., Zheng, S., Yang, G., Zheng, M., Wu, J., Qi, S., Shen, G., Tang, L., Yin, Y., Zhao, T., Yu, H., Liu, D., Zhao, D., Zhang, T., Ruan, J., \& Huang, M. (2018). Substantial reductions in ambient PAHs pollution and lives saved as a co-benefit of effective long-term $\mathrm{PM}_{2}$ pollution controls.

Environment International, 114, 266-279. https://doi.org/10.1016/j.envint.2018.03.0\%2

\section{Published in:}

Environment International

\section{Citing this paper}

Please note that where the full-text provided on Manchester Research Explorer is the Author Accepted Manuscript or Proof version this may differ from the final Published version. If citing, it is advised that you check and use the publisher's definitive version.

\section{General rights}

Copyright and moral rights for the publications made accessible in the Research Explorer are retained by the authors and/or other copyright owners and it is a condition of accessing publications that users recognise and abide by the legal requirements associated with these rights.

\section{Takedown policy}

If you believe that this document breaches copyright please refer to the University of Manchester's Takedown Procedures [http://man.ac.uk/04Y6Bo] or contact uml.scholarlycommunications@manchester.ac.uk providing relevant details, so we can investigate your claim.

\section{OPEN ACCESS}


4 Shaofei Kong ${ }^{1,2}{ }^{*}$, Qin Yan ${ }^{3}$, Huang Zheng ${ }^{1}$, Haibiao Liu ${ }^{3}$, Wei Wang ${ }^{3}$, Shurui Zheng ${ }^{1}$,

5 Guowei Yang ${ }^{1}$, Mingming Zheng ${ }^{1}$, Jian Wu ${ }^{1}$, Shihua Qi ${ }^{4}$, Guofeng Shen ${ }^{5,}{ }^{*}$, Lili Tang ${ }^{6}$, Yan

6 Yin ${ }^{2,3}$, Tianliang Zhao ${ }^{2,3}$, Huan Yu ${ }^{7}$, Dantong Liu ${ }^{8}$, Delong Zhao ${ }^{9}$, Tao Zhang ${ }^{10}$, Jujun Ruan ${ }^{10}$,

7 Mingzhi Huang ${ }^{11}$

8

9

1. Department of Atmospheric Science, School of Environmental Studies, China University of Geosciences, Wuhan 430074, China

2. Collaborative Innovation Center on Forecast and Evaluation of Meteorological Disasters, Nanjing University of Information Science and Technology, Nanjing 210044, China

3. College of Atmospheric Physics, Nanjing University of Information Science \& Technology, Nanjing 210044, China

4. State Key Laboratory of Biogeology and Environmental Geology, China University of Geosciences, Wuhan 430074, China

5. College of Urban and Environmental Sciences, Peking University, 100871, Beijing

6. Jiangsu Environmental Monitoring Center, Nanjing 210036 China

7. School of Environmental Science and Engineering, Nanjing University of Information Science and Technology, Nanjing, China

8. School of Earth, Atmospheric \& Environmental Sciences, University of Manchester, UK

9. Beijing Weather Modification Office, Beijing 100089, China

10. School of Environmental Science and Engineering, Sun Yat-Sen University, Guangzhou 510275, China

11. Environmental Research Institute, South China Normal University, Guangzhou, 510631, China

* Correspondence to: Prof. Shaofei Kong (kongshaofei@cug.edu.cn) or Dr. Guofeng Shen (gfshen12@gmail.com) 
Abstract:

Under great efforts in fighting against serious haze problem of China since 2013, decreasing of air pollutants especially for fine particles $\left(\mathrm{PM}_{2.5}\right)$ has been revealed for several key regions. This study tried to answer whether the reduction of $\mathrm{PM}_{2.5}$-bound polycyclic aromatic hydrocarbons (PAHs) was coincident with $\mathrm{PM}_{2.5}$ because of long-term pollution control measures (PCM), and to assess source-oriented health risks associated with inhalation exposure to PAHs. Field measurements were carried out before and after the publishing of local air pollution protection plan for Nanjing, a mega-city in east China. Results indicated that the air quality was substantially improving, with a significant reduction in annual average $\mathrm{PM}_{2.5}$ by $34 \%$, and moreover, $\mathrm{PM}_{2.5}$-bound $\mathrm{PAHs}$ significantly reduced by $63 \%$ $(p<0.001)$. The remarkable reduction was mainly attributable to the change of emission sources, compared to the influence of atmospheric circulation patterns, surface meteorological conditions, and atmospheric chemical reaction. Four PAHs sources including coal combustion (CC), petroleum and oil burning (PO), wood burning (WB) and vehicle emission (VE) were identified. On an annual basis, contributions to ambient $\mathrm{PM}_{2.5}-\mathrm{PAHs}$ from $\mathrm{WB}, \mathrm{PO}, \mathrm{CC}$ and $\mathrm{VE}$ sources in the period before the action of control measures were $2.26,2.20,1.96$ and $5.62 \mathrm{ng} \mathrm{m}^{-3}$, respectively. They reduced to $1.09,0.37,1.31$ and $1.77 \mathrm{ng}$ $\mathrm{m}^{-3}$ for the four source types, with the reduction percentages as $51,83,33$ and $68 \%$, respectively. The estimated reduction in lifetime lung cancer risk was around $61 \%$. The study that firstly assessed the health effects of PAHs reduction as a co-benefit raised by air PCM sustained for a long period is believed to be applicable and referential for other mega-cities around the world for assessing the benefits of PCM.

Keywords: air pollution control; $\mathrm{PM}_{2.5}$-bound $\mathrm{PAHs}$; source apportionment; exposure risk assessment; source-oriented risk allocation 


\section{Introduction}

China is one of the regions holding the highest atmospheric fine particle $\left(\mathrm{PM}_{2.5}\right)$ concentrations of the world (Donkelaar et al., 2015; Cheng et al., 2016). The Chinese government has been trying to mitigate air pollution for nearly thirty years since the 1980s (Feng and Liao, 2016). In 2012, when the new ambient air quality standard was released, $\mathrm{PM}_{2.5}$ pollution has attracted worldwide attention for both scientists and decision makers, especially after the extremely severe and long-lasting haze pollution event occurred in January 2013 (Fu and Chen, 2017; Wang et al., 2017a). In September 2013, the national "Action Plan on Atmospheric Pollution Prevention and Control (APPC)" was promoted, in which the main reduction measures for $\mathrm{PM}_{2.5}$ emphasized mainly on coal combustion, industrial manufacturing processes, urban/suburban fugitive dust, cooking activities, vehicle exhaust and fuel quality. It was predicted the implementation of these measures could reduce $\mathrm{PM}_{2.5}$ emission by $30 \%$ in 2017 relative to 2012 in the Beijing-Tianjin-Hebei region (Cai et al., 2017). It is important and of growing interests to assess the effectiveness of pollution control measures (PCM) on air quality, either for a long-term period (Chen et al., 2016a; Wang et al., 2017a, b), short-term serious air pollution episodes (Xu et al., 2016a; Wang et al., 2017c), or during specific short-term mega-events like APEC (Guo et al., 2016; Wang et al., 2017d). However, to our knowledge, few researchers concerned the role of PCM in potential reductions of toxic chemical components in $\mathrm{PM}_{2.5}$, such as heavy metals (Chen et al., 2016b; Li et al., 2016b), black carbon (BC) (Chen et al., 2016c)/elemental carbon (EC) (Wang et al., 2017b) and polycyclic aromatic hydrocarbons (PAHs) (Wang et al., 2011; Xu et al., 2013), which have significant health impacts.

PAHs are a group of organic contaminants formed in nearly all in-complete combustion processes and can be long-range transported in the air (Shrivastava et al., 2017). Carcinogenic and teratogenic PAHs are associated with many adverse health outcomes like increased levels of oxidative stress (Bae et al., 2010), gastroschisis (Lupo et al., 2012), ischaemic heart disease (Burstyn et al., 2005), systemic inflammation (Delfino et al, 2010), adverse health symptoms in survivors of myocardial infarctions (Kraus et al, 2011) and children's cognitive development (Edwards et al., 2010), obesity (Scinicariello and Buser, 2014) and behavior development (Perera et al., 2012). Since the implementation of APPC from 2013 of China (totally ten types of measures including thirty-five sub-items were published in APPC), sources of $\mathrm{PM}_{2.5}$ changed significantly. 
For PCM of APPC, coal combustion, industrial processes, cooking activities, biomass burning, and vehicle emissions are in fact the key sources for atmospheric PAHs (Zhang and Tao, 2009). Therefore, it is believed that PAHs sources may exhibit notable changes as well. It is essential to access to what extent the PAHs concentrations and associated health risk that could be reduced when these control measures for $\mathrm{PM}_{2.5}$ are implemented at a certain city or region, and it is interesting to clarify whether the decreasing trends of $\mathrm{PM}_{2.5}$ and PAHs are same or not. Investigation into the main sources leading to the decreasing of PAHs concentrations and risks and identification roles of influencing factors like meteorological conditions, photochemical reaction and source changes in the variations of PAHs are valuable for the evaluation of PCM. It is also informative for the future researches and policymaking.

Since 2013, the four-year solid efforts to reduce source emissions of air pollutants especially for $\mathrm{PM}_{2.5}$ in Nanjing (an industrial city and one of the central megacities located in the Yangtze River Delta (YRD) region) provided a unique opportunity to study the variation in $\mathrm{PM}_{2.5}$-bound PAHs concentrations, as well as the associated risks. A campaign from 2013 to 2016 covered two distinguished periods of March 2013-February 2014 (Period 1) and November 2015-July 2016 (Period 2), that was before and after the AR-APPC (Administrative Rules of Nanjing for further strengthening the APPC) in Nanjing. The AR-APPC was proposed at February 2014 and issued from April 2015. In the APPC of Nanjing published of 2014, six types of control measure were proposed, including optimizing the industrial structure and layout, improving energy structure, strengthening industrial pollution prevention and control, developing green transportation, control fugitive dust, and control pollution from agricultural and human activities (Table S1). The initial target of this AR-APPC is to reduce the annual mass concentration of $\mathrm{PM}_{2.5}$ in Nanjing by $7 \%, 13 \%$ and $20 \%$ in 2015,2016 and 2017 relative to that in 2013, respectively.

The main objectives of this paper are: (1) to evaluate the reduction of air pollutants and PAHs in Nanjing; (2) to identify the variation in PAHs concentrations, markers, chemical degradation and sources; (3) to interpret the reasons for PAHs variation in view of source emission and meteorological conditions; and (4) to quantify the potential health risk reductions of PAHs and allocated it to various sources. To our knowledge, this is the first and maybe the only research to evaluate the PAHs concentrations of the four years since 2013 in 
120 China. It is helpful to expand the understanding of co-benefits of PCM for $\mathrm{PM}_{2.5}$, which has

121 important enlightenment for regional or city-level assessment of air quality improvement.

122 2. Method

$123 \quad 2.1$ Site description and $\mathbf{P M}_{2.5}$ sampling

124 Ambient $\mathrm{PM}_{2.5}$ samples were collected on top of a seven-floor building ( $20 \mathrm{~m}$ above the 125 ground) of Jiangsu Academy of Environmental Sciences. In Period 1, samples were collected 126 during March, June, and September in 2013 and January in 2014, to represent four seasons of 127 spring, summer, autumn and winter. In each season, the sampling lasted for about one week. The 128 sampling flow was $\sim 16.7 \mathrm{~L} \mathrm{~min}^{-1}$ (Wuhan Tianhong Ltd., China). In Period 2, $\mathrm{PM}_{2.5}$ samples were 129 collected on a rooftop of Jiangsu Environmental Monitoring Center (JEC, a six-floor building, 130 about $15 \mathrm{~m}$ above the ground) at a flow rate of $\sim 100 \mathrm{~L} \mathrm{~min}^{-1}$ (TH-150C, Wuhan Tianhong Ltd., 131 China) (Kong et al., 2015a, 2015b) during November of 2015 and January, April and July of 2016. 132 The sampling lasted for about 7-14 days in each season. The two sampling sites are $0.5 \mathrm{~km}$ away 133 in the distance, at two close blocks. It is a typical traffic/residential region of urban Nanjing, with 134 residential communities surrounded. There is a steel factory about $15 \mathrm{~km}$ to the north of the site 135 and two chemical industry parks about $20 \mathrm{~km}$ to the north and northwest. Within the distance from $13620 \mathrm{~km}$ of the sampling sites, some power plants and industrial plants existed, mostly concentrated 137 in the north, west and south direction. Location of the sampling sites and surrounding major 138 sources are shown in Figure. 1.

139 Each day, the $\mathrm{PM}_{2.5}$ sampling lasted for $\sim 24 \mathrm{~h}$ (starting from about 08:00) for both the two 140 periods, with quartz fiber filters used. Filters were sealed in aluminum foil bags and weighted by a 141 microbalance (Ohaus Discovery DV214CD) with the balance under controlled environment and stored under $-20{ }^{\circ} \mathrm{C}$ until laboratory analysis. The detailed treatment method of the filters was listed in Kong et al. (2015a, 2015b).

2.2 Meteorological and air quality data acquisition

The meteorological parameters including ambient temperature (T), relative humidity (RH), wind speed $\left(\mathrm{W}_{\mathrm{S}}\right.$ ) and visibility (Vs) were obtained from the Nanjing Meteorological Bureau. The

147 precipitation information was collected from http://www.wunderground.com/. The daily averaged mass concentrations of $\mathrm{PM}_{2.5}, \mathrm{PM}_{10}, \mathrm{SO}_{2}, \mathrm{NO}_{2}, \mathrm{CO}$, and $\mathrm{O}_{3}$ were collected from the supersite on 
carbon (OC) and elemental carbon (EC) were monitored by Sunset Laboratory Semi-Continuous OC/EC Carbon Aerosol Analyzer (Sunset-OCEC, RT-4) in Jiangsu Environmental Center and the corresponding data for sampling periods were provided. For assessing the air quality variation in Nanjing, the daily averaged mass concentrations of $\mathrm{PM}_{2.5}, \mathrm{PM}_{10}, \mathrm{SO}_{2}, \mathrm{NO}_{2}$ and $\mathrm{CO}$ for nine air quality monitoring sites (the nine sites can be found at http://106.37.208.233:20035/) were provided from 1/January/2013 to 30/December/2016. The 8-hours moving average value of $\mathrm{O}_{3}$ was used for each day.

\subsection{Laboratory PAHs analysis and quality controls}

Laboratory PAHs analysis was the same as that described in Kong et al. (2015b). Briefly, filters were extracted ultrasonically with dichloromethane, concentrated using a rotary evaporator, and then transferred to a silica gel for cleanup and purification. The elutes were finally concentrated to $\sim 1 \mathrm{~mL}$ under a gentle nitrogen stream and then spiked with internal standards prior to instrument analysis. PAHs analyzed by a trace 2000 GC-MS (Thermo Finnigan, USA) operated in selected ion monitoring (SIM) model. Totally 18 PAHs were detected including naphthalene (NaP, 2-ring), acenaphthylene (Acy, 3-ring), acenaphthene (Ace, 3-ring), fluorene (Fl, 3-ring), phenanthrene (Phe, 3-ring), anthracene (Ant, 4-ring), fluoranthene (Flu, 4-ring), pyrene (Pyr, 4-ring), benzo[a]anthracene (BaA, 4-ring), chrysene (Chr, 4-ring), benzo[b]fluoranthene (BbF, 5-ring), benzo[k]fluoranthene (BkF, 5-ring), benzo[a]pyrene(BaP, 5-ring), Benzo(e)pyrene (BeP, 5-ring), dibenz[a,h]anthracene (DBA, 6-ring), indeno[1,2,3-cd]pyrene (InP, 6-ring), benzo[ghi]perylene (BghiP, 6-ring) and coronene (Cor, 7-ring). 2 and 3-ring PAHs are attributed to low molecular weight PAHs (LPAHs). 4-ring PAHs belong to medium molecular weight PAHs (MPAHs) and high molecular weight PAHs (HPAHs) contain 5-, 6and 7-ring PAHs. Two types of PAHs are also paid attention, named as combustion-derived PAHs (COMPAHs), including Flu, Pyr, Chr, BbF, BkF, BaA, BeP, BaP, InP and BghiP and carcinogenic PAHs (C-PAHs) including $\mathrm{Chr}, \mathrm{BaA}, \mathrm{BbF}, \mathrm{BkF}, \mathrm{BaP}, \mathrm{InP}$ and DBA (Kong et al., 2015b; Wang et al., 2015).

For quality assurance and quality control, field blank and laboratory blank filters were treated following the same procedure in regular samples. Quantification of PAHs was done by the retention times and peak areas of the calibration standards. Internal standard method 

was used. Reserve liquid (1000 mg/L) including Perylene-d12, Chrysene-d12, Acenaphthene-d12, Naphthalene-d8 and Phenanthrene-d10 was diluted by n-hexane to $20 \mathrm{mg} / \mathrm{L}$ and was stored below $4^{\circ} \mathrm{C}$. The recovery test was performed by spiking known amounts of a mixture of PAHs and then the spiked filter was treated the same way as mentioned above. The recoveries of each PAHs were in $81 \%-93 \%$, and the relative standard deviation was less than $10 \%$. The detection limits for the 18 kinds of PAHs ranged between 3.0-10.0 ng. Results reported were subtracted from blanks, but not corrected by recoveries.

\subsection{Back trajectory and mixing layer height calculation}

Backward air mass trajectories $(72 \mathrm{~h}$ ) with the starting height of $500 \mathrm{~m}$ are calculated using NOAA Air Resource Lab HYSPLIT 4.8 model, driven by the GDAS meteorological dataset $\left(1^{\circ} \times 1^{\circ}\right)($ Wang et al., 2016b; Ye et al., 2017). To achieve the sub-sets of trajectories, the backward trajectories computed every six hour (00:00, 06:00, 12:00 and 18:00) each day were clustered. Clustering process is listed in Hysplit User' s Guide-Version 4. On the NOAA's READY Archived Meteorology online calculating program (http://ready.arl.noaa.gov/READYamet.php), the mixing layer height (MLH) was calculated every three hour per day.

\subsection{PAHs source apportionment}

Positive matrix factorization (PMF) model is adopted to investigate PAHs sources. As a multivariate factor analysis tool, it decomposes a matrix of speciated sample data into factor contribution matrix $(\mathrm{G})$ and factor profile matrix $(\mathrm{F})$, and is expressed as follows:

$$
x_{i j}=\sum_{k=1}^{p} g_{i k} f_{k j}+e_{i j}
$$

where $x_{i j}$ is the concentrations of $j$ th PAHs species in the ith sample; $g_{i k}$ is the contribution of the $k t h$ source to the $i t h$ sample; $f_{k j}$ is the mass fraction of the $j t h$ compound from the $k t h$ source; $e_{i j}$ is the residual for each sample/species. US Environmental Protection Agency PMF version 5.0 was adopted. Detailed PMF running description was listed in Supplementary file S1 (including Figure S1, Table S2-S4).

\subsection{Potential source contribution function and concentration weighted trajectory}

Potential source contribution function (PSCF) and concentration weighted trajectory (CWT) were adopted to evaluate the influence of regional PAHs sources and were calculated with the 
software Traj-Stat, based on the daily source contributions and backward trajectories. Weighted-PSCF (WPSCF) values were calculated by multiplying PSCF values with a weighting function. A concentration-weighted-trajectory (CWT) model was introduced to add additional information on source contribution levels of different potential regions. WPSCF and weighted CWT (WCWT) were adopted for discussion. The detailed description of PSCF and CWT calculation was listed in Supplementary file S2.

\subsection{Health risk assessment}

Potential health risks of PAHs via inhalational exposure have been widely characterized by calculating incremental lifetime cancer risk (ILCR) as:

$$
I L C R=U R_{B a P} \times B a P_{e q}
$$

$$
B a P_{e q}=\sum_{i=1}^{n}\left(C_{i} \times T E F_{i}\right)
$$

where $U R_{B a P}$ is the unit cancer risk factor of $\mathrm{BaP}$, as $8.7 \times 10^{-5}$ per $\mathrm{ng} \mathrm{m}^{-3}$ (Callén et al., 2014; Chen et al., 2016a; Yu et al., 2016; Pereira et al., 2017); $C_{i}$ is the concentration of PAHs species $\left(\mathrm{ng} \mathrm{m}^{-3}\right)$; $\mathrm{BaPeq}$ is the $\mathrm{BaP}$ equivalent concentration $\left(\mathrm{ng} \mathrm{m}^{-3}\right)$, which is calculated by multiplying the $C_{i}$ with their corresponding toxic equivalent factor $\left(T E F_{i}\right)$. The $T E F_{i}$ was selected as 0.001 for NaP, Acy, Ace, Fl, Phe, Flu and Pyr, 0.01 for Ant, Chr, BeP and BghiP, 0.1 for BaA, BbF, BkF, and InP, and 1 for BaP and DBA (Khan et al., 2015; Zhu et al., 2015; Chen et al., 2017).

\section{Results and discussion}

\subsection{Criteria air pollutants and meteorological conditions before and after the AR-APPC}

In Table 1, there were no significant differences in average ambient temperature, Ws, RH and MLH between the two periods, while visibility significantly decreased by $34 \%$ $(p<0.001)$ in Period 2. The average concentrations of $\mathrm{PM}_{2.5}, \mathrm{PM}_{10}$ and $\mathrm{O}_{3}$ for the Period 2 significantly reduced by $34 \%(p<0.001), 34 \%(p<0.001)$ and $18 \%(p<0.05)$, respectively, in comparison with those for Period 1 (Table 2). There were no significant changes of the other criteria gaseous pollutants like $\mathrm{CO}, \mathrm{SO}_{2}$, and $\mathrm{NO}_{2}$. From the evaluation report on air quality published by Ministry of Environmental Protection of China, reduction of $\mathrm{PM}_{2.5}$ could be clearly found for YRD region from 2013 to 2016 (Figure S2). As expected, the average annual mass concentrations of $\mathrm{PM}_{2.5}, \mathrm{PM}_{10}, \mathrm{SO}_{2}$, and $\mathrm{NO}_{2}$ in Nanjing were all decreasing 
gradually from 2013 to 2016, by 38\%, 38\%, 50\% and 20\%, respectively (Figure 2). It has successfully achieved the goal of $20 \%$ reduction for $\mathrm{PM}_{2.5}$ proposed in the AR-APPC. The reduction rate of $\mathrm{PM}_{2.5}$ for the whole Nanjing was similar with that for the given site and sampling periods of this study. Though the decreasing rate was high to $59 \%$ for the $\mathrm{PM}_{2.5}$ in the winter season of the two periods, $\mathrm{PM}_{2.5}$ concentration in winter was still highest as $72.5 \pm 37.7 \mu \mathrm{g} \mathrm{m}^{-3}$ in Period 2. It indicated that the current regulations for winter should be enforced more rigorously, exactly and beneficially.

\subsection{Comparison of ambient PAHs before and after the AR-APPC}

As shown in Figure. 3, the overall averaged PAHs concentrations were significantly reduced by $63 \%(p<0.001)$ at Period 2 , higher than that of $34 \%$ for $\mathrm{PM}_{2.5}$ mass concentrations. The averaged COMPAHs and C-PAHs exhibited concentration reductions of 55\% and 60\% $(p<0.001)$. Significant reductions were also observed for the averaged concentrations of each PAHs individual, ranging from $45 \%$ to $87 \%(p<0.01)$. To eliminate the influence of meteorological conditions, PAHs mass concentration was normalized by $\mathrm{PM}_{2.5}$ concentration (Anastasopoulos et al., 2012; Kong et al., 2015b; Wang et al., 2015) and Ws (Wang et al., 2016a). Ratios of $\mathrm{PAHs} / \mathrm{PM}_{2.5}$ and PAHs/Ws were statistically lower for Period 2, with the decreasing rates of $82 \%$ $(p<0.01)$ and $57 \%(p<0.001)$, respectively. This confirmed the substantial decrease of PAHs for Period 2 and the decreasing rate of PAHs was larger than that of $\mathrm{PM}_{2.5}$. It indicated that the PCM for $\mathrm{PM}_{2.5}$ had played a positive role in PAHs reduction. Now the annual averaged PAHs concentrations of Nanjing $\left(4.61 \pm 3.29 \mathrm{ng} \mathrm{m}^{-3}\right)$ were comparable to the reported levels in Thessaloniki (4.66 $\mathrm{ng} \mathrm{m}^{-3}$ ) (Saffari et al., 2013), Hong Kong (4.59 $\mathrm{ng} \mathrm{m}^{-3}$ ) (Ma et al., 2016) and Shanghai (6.49 $\mathrm{ng} \mathrm{m}^{-3}$ ) (Wang et al., 2016b) and were lower than most of those in other cities as compiled in Table S5.

As the most carcinogenic PAHs, the averaged concentrations of $\mathrm{BaP}$ decreased by $57 \%$ $(\mathrm{P}<0.001)$ for Period 2 when compared with that of Period 1 (Table 3). The ambient BaP in urban Nanjing was continuously decreasing during the last two decades. The averaged $\mathrm{BaP}$ in 2001 was $8.05 \mathrm{ng} \mathrm{m}^{-3}$ (September, an urban site) (Yang et al., 2005), $4.17 \mathrm{ng} \mathrm{m}^{-3}$ in 2001/2002 (five urban sites, whole year) (Wang et al., 2006a), $3.83 \mathrm{ng} \mathrm{m}^{-3}$ in 2004 (summer and winter, an urban site) (Wang et al., 2007), $3.73 \mathrm{ng} \mathrm{m}^{-3}$ in 2009/2010 (from November 2009 to July 2010, one urban and one suburban site) (He et al., 2014), $0.65 \mathrm{ng} \mathrm{m}^{-3}$ in 2013/2014 (this study) and $0.27 \mathrm{ng} \mathrm{m}^{-3}$ in 
2015/2016 (this study), respectively. The annual averaged guideline value of $\mathrm{BaP}$ recommended by the World Health Organization and European Union was $1 \mathrm{ng} \mathrm{m}^{-3}$ (Ravindra et al., 2008; Wang et al., 2017d). The annual BaP concentration of Nanjing is now below the guideline value. From 2001/2002 to 2009/2010, the variation of BaP is little, decreased by $10.5 \%$. While from $2009 / 2010$ to $2013 / 2014$, obvious decreasing by $83 \%$ was found. We can deduce that the reduction of PAHs may be a longer-term trend in the first decade. While after 2009/2010, the reduction rate accelerated. There should be other forcing favored it, which should be the proposed PCM for air pollutants after 2013. The effective PAHs reduction along with the air pollution control strategies during short-term mega-events was also reported (Wang et al., 2011; Xu et al., 2013; Li et al., 2016c).

From Table 3, clear seasonal variations were observed, with highest PAHs concentrations in winter and lowest concentrations in summer. The winter/summer ratios of PAHs were averaged as 3.3 and 4.7 for Period 1 and Period 2, respectively. PAHs/PM 2.5 exhibited the similar winter and summer variation. This seasonal variation pattern has been widely reported in former studies (Marchand et al., 2004; Wang et al., 2006b; Akyüz and Çabuk, 2008; Guo et al., 2009; Martellini et al., 2012; Mancilla et al., 2016; Yu et al., 2016). Following reasons could explain the seasonal variations in PAHs in this study: (1) additional emissions in winter from residential heating with coal and wood as fuels in North China (Wang et al., 2006b; Chen et al., 2016a; Lin et al., 2015; Lv et al., 2016), which can transport and affect air quality of Nanjing (detailed discussion in Section 3.4 .2 and 3.4.3); (2) reduced atmospheric dispersion due to inversion and lower MLH in winter (as $312 \pm 124$ and $445 \pm 187$ $\mathrm{m}$ for winter of the two periods, respectively); (3) enhanced partition to particles under lower temperature; (4) less pronounced photochemical degradation processes in winter as low ambient temperature (discussion in Section 3.3.2) (Marchand et al., 2004; Chen et al., 2016a). The change exited in not only total PAHs mass concentration but also the PAHs composition profile. It can be observed that the overall averaged mass percentage of LPAHs ( 2 and 3 ring PAHs) decreased from $25 \%$ to $14 \%$ (decreased by $44 \%, p<0.001$ ), the overall averaged MPAHs (4 ring PAHs) increased from $22 \%$ to $32 \%$ (increased by $44 \%, p<0.001$ ) and the HPAHs (5, 6 and 7 ring PAHs) varied a little bit (from 53\% to 54\%) (Figure 3). Generally, higher LPAHs concentration was related to non-combusted petroleum emission 
and HPAHs were mainly from fossil fuel combustions (He et al., 2014). It can be inferred that petroleum emission of PAHs reduced after the AR-APPC.

3.3 Difference in meteorological conditions, atmospheric chemical degradation and sources between the two periods

\subsubsection{The role of circulation patterns, surface meteorological parameters and long-range} transportation

The circulation patterns can influence the air quality through transport pathways and determine local meteorology (Xu et al., 2016a). The circulation patterns (seasonal mean geopotential height and wind vectors at $10 \mathrm{~m}$ above sea level) for four seasons of the two periods were illustrated in Figure S3. At first glance, the circulation patterns of the two periods were similar for all the four seasons. In autumn and winter, Nanjing was under control of Siberian high pressure and it was stronger for Period 2 than that of Period 1, which was the typical features of East Asian winter (Kim et al., 2016). The main backward trajectory clusters of the four seasons were also similar for the two periods (Figure S4), with north and northwest trajectories dominated in winter and autumn. Thus, the air pollutants at Nanjing were easily affected by the upstream transport at the northwest direction and the impact was more profound in Period 2 at the two seasons. It should be noted that in later autumn and winter period, the North China area exhibits high coal consumptions (Figure S5) and high emission densities of many air pollutants from biomass burning (Zhou et al., 2017). Meanwhile, weak negative correlations were found between PAHs and temperature and MLH, especially for higher rings PAHs (Table S6, Figure S6). As shown in Figure S6, high rings PAHs also exhibited weak positive correlations (most P values lower than 0.01) with $\mathrm{SO}_{2}, \mathrm{NO}_{2}, \mathrm{OC}$, and $\mathrm{EC}$, that originated mainly from combustion sources (Thornhill et al., 2008; Mancilla et al., 2016). All these can verify the higher PAHs concentrations in winter. Furthermore, above analysis highlighted the importance of coal and biomass burning in north China at cold periods on affecting the PAHs concentrations in Nanjing. For yearly variation, as there were no significant differences in temperature and MLH between the two periods, the role of them in explaining PAHs reduction may be limited.

\subsubsection{The role of atmospheric chemical degradation and particle coatings}

During the atmospheric transportation, PAHs compounds are exposed to oxidants, such as $\mathrm{O}_{3}$, $\mathrm{OH}, \mathrm{NO}_{2}$ and nitric acid, which degrade PAHs and thereby change the PAHs compositions and 
concentrations (Thornhill et al., 2008; Dvorská et al., 2011; Gao et al., 2011) and the reaction rate is depended on the particle compositions and meteorological factors. $\mathrm{BaP} / \mathrm{BeP}$ ratio is often used as an indicator of the aging process, as $\mathrm{BaP}$ degradation is typically faster than $\mathrm{BeP}$ in the air (Ravindra et al., 2008; Pinxteren et al., 2009). In this study, $\mathrm{BaP} / \mathrm{BeP}$ ratio significantly increased from $0.45 \pm 0.15$ (Period 1) to $0.70 \pm 0.15$ (Period 2) $(p<0.001)$. This may suggest that PAHs at Period 1 were more aged than those of Period 2, which was consistent with a higher $\mathrm{O}_{3}$ concentration of Period 1. This may further indicate that the difference in the "initial" ambient PAHs level between the two periods could be even higher than the reduction calculated based on observed concentration now.

In some previous studies, $\mathrm{PAHs/EC} \mathrm{ratio} \mathrm{was} \mathrm{suggested} \mathrm{to} \mathrm{indicate} \mathrm{the} \mathrm{photochemical}$ degradation of PAHs. Kong et al. (2012) systematically investigated the emission of PAHs and inorganic chemical components in $\mathrm{PM}_{2.5}$ of various sources and the $\mathrm{PAHs} / \mathrm{EC}$ ratios for different sources were shown in Figure S7. For all the sources except for gasoline vehicle

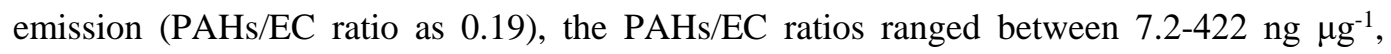
which were much higher than the ratios of ambient air of this study (3.31 \pm 2.34 for Period 1 and $1.20 \pm 0.72$ for Period 2), further verifying the aging of PAHs. The PAHs/EC ratio is typically low under high $\mathrm{O}_{3}$ concentrations and high temperature due to stronger photo-degradation of PAHs (Figure S8). In this study, although the $\mathrm{O}_{3}$ concentrations were significantly decreased at Period 2, the PAHs/EC values did not exhibit higher values as expected. Conversely, it was significantly lower than that of Period $1(\mathrm{P}<0.001)$. This appears to say that PAHs from the Period 2 were more aged compared to those in Period 1. One reason is that source profiles were believed to be changed from the Period 1 to Period 2, thus a direct comparison of the overall average $\mathrm{PAHs} / \mathrm{EC}$ ratios may be inappropriate here to indicate the aging degree between the two studied periods. Decreased emission of PAHs from oil evaporation (which do not contribute to EC) as pollution control at Period 2 can lead to lower PAHs/EC ratio, and increased relatively contributions from vehicle emissions would lower the ratio as well. In fact, even though the sources were not changed or similar, a simple comparison based solely on the $\mathrm{PAHs} / \mathrm{EC}$ ratio and/or their dependence on ambient $\mathrm{O}_{3}$ may be biased and associated with high uncertainty, because: (1) $\mathrm{O}_{3}$ can only partly explain the PAHs losses and the role of $\mathrm{OH}$ and other oxidants (like $\mathrm{NO}_{2}$ ) in PAHs photolysis can also 
dominate the PAHs losses (Marchand et al., 2004); (2) the coating effects of fresh particles with secondary aerosols which can shield PAHs from chemical degradation (Thornhill et al., 2008; Shrivastava et al., 2017). Thornhill et al. (2008) used a criterion of (PAHs+10)/BC $>11 \mathrm{ng}^{-1} \mathrm{~g}^{-1}$ to identify data points representing uncoated particles. In this study, the values of (PAHs+10)/EC were $6.16 \pm 2.77$ and $4.00 \pm 1.19 \mathrm{ng}^{-1} \mathrm{~g}^{-1}$ for Period 1 and Period 2, respectively, indicating the particle phase PAHs were both coated by secondary aerosols for the two periods.

Therefore, it is believed that the measured PAHs for both the two periods were aged. However, it is difficult to quantitatively evaluate and compare the degree of photochemical aging in the present study. Considering the comparable $\mathrm{O}_{3}$ and $\mathrm{NO}_{2}$ concentrations and similar meteorological conditions of the two periods, it is believed the photochemical degradation played a limited role in explaining the significant reduction of averaged mass concentrations of PAHs from Period 1 to Period 2 in this study.

\subsubsection{The role of pollution control measures}

In China, the PCM is initially to reduce the regular air pollutants of $\mathrm{CO}, \mathrm{SO}_{2}, \mathrm{NO}_{\mathrm{x}}, \mathrm{PM}_{2.5}$, $\mathrm{PM}_{10}$, and VOCs. The higher reduction rate of $\mathrm{PM}_{2.5}$ associated PAHs than $\mathrm{PM}_{2.5}$ itself observed in this study indicated that effective controls could have a positive influence on ambient PAHs pollution. According to the report of Nanjing Environmental Protection Bureau, the main sources of $\mathrm{PM}_{2.5}$ in Nanjing were coal combustion (27.4\%), industrial production (19.0\%), vehicle emission (24.6\%), fugitive dust (14.1\%) and other sources (14.9\%) in 2014 (http://jsnews2.jschina.com.cn/system/2015/04/30/024548067.shtml). A series of emission sources have been controlled or improved after 2015 (Table S7). The total coal consumption was controlled to below 30 million tons. The gasoline, gasoline oil and solvent oil consumption amount decreased by $15.6 \%, 8.6 \%$ and $54.1 \%$ in 2015 when compared with those in 2013 . The use of clean energy like coal gas and natural gas increased by $24.3 \%$ and $7.4 \%$, respectively. Meanwhile, many improving measures were adopted for coal and oil burning, industrial processes and domestic activities, etc. These all lead to the reduction of $\mathrm{PM}_{2.5}$ and also associated PAHs. Sources of $\mathrm{PM}_{2.5}$ could be more complex than those of PAHs. The significant weak positive correlations between high ring PAHs (4-7 rings) and $\mathrm{SO}_{2}, \mathrm{NO}_{2}$, $\mathrm{OC}$ and $\mathrm{EC}$ (Figure S6) indicating that there may exist similar sources of PAHs with the precursors and key components of $\mathrm{PM}_{2.5}$. However, their sources were not the same. No significant correlations were found for 2 and 3 ring 
PAHs with $\mathrm{SO}_{2}, \mathrm{NO}_{2}, \mathrm{OC}$, and $\mathrm{EC}$, suggesting different sources or formation pathways. Therefore, the control measures of $\mathrm{PM}_{2.5}$ and its precursors may not play the same role for PAHs reduction of different rings, which can explain the difference in reduction rate of $\mathrm{PM}_{2.5}$ (34\%) and PAHs (63\%) in this study.

PAHs markers are powerful to identify and attribute emission sources (Mancilla et al., 2016). Typical PAH markers were Chr, BkF, Flu, Pyr, BaA and BaP for coal burning (Bourotte et al., 2005; Ravindra et al., 2008; Teixeira et al., 2015); Acy, Ant, Phe, Flu, Pyr, Chr, BbF and BkF for wood burning (Marchand et al., 2004; Bourotte et al., 2005; Teixeira et al., 2015); BghiP, Cor and InP for gasoline emission (Pinxteren et al., 2009; He et al., 2014; Shen et al., 2014; Pereira et al., 2017); Flu, Pyr, Chr, BbF, BkF and BeP for diesel emission (Marchand et al., 2004; Bourotte et al., 2005; He et al., 2014; Mancilla et al., 2016); Pyr, BaP and BaA for natural gas combustion (Bourotte et al., 2005) and Pyr, Flu and Phe for incineration (Ravindra et al., 2008). We summed the concentrations of these markers and adjusted to $\mathrm{PM}_{2.5}$ mass concentration for each source type of the two periods. The calculated ratios were significantly reduced for sources including wood burning (Acy, Ant, Phe, Flu, Pyr, $\mathrm{Chr}, \mathrm{BbF}$ and $\mathrm{BkF})(p<0.05)$, gasoline vehicle emission (BghiP, Cor and $\mathrm{InP})(p<0.01)$ and diesel vehicle emission (Flu, Pyr, $\mathrm{Chr}, \mathrm{BbF}, \mathrm{BkF}$ and $\mathrm{BeP})(p<0.05)$. This indicated that the PCM played an effective role in reducing the contributions of wood burning and vehicle emission to PAHs in Nanjing. The open biomass burning was strictly monitored and forbidden in recent years. For coal combustion, many efforts have been made mainly for industrial activities in China, while the pollutants control from domestic coal burning was still limited, which can contribute $10.7 \%$ of PAHs emission of China (Zhang and Tao, 2009). For vehicle emission, the improved fuel quality (lower sulfur and aromatic content) (Ravindra et al., 2008), the adoption of catalytic converters (Ravindra et al., 2008), the adoption of clean energy vehicles, eliminating the vehicles which cannot meet the higher emission standards and so on all make fundamental contributions to the PAHs reduction. In short, along with the economic and social development, though more energies are consumed, the PAHs concentrations can be effectively reduced with comprehensive pollution control measures for $\mathrm{PM}_{2.5}$. 
To sum up, as the similarity in the circulation patterns and surface meteorological parameters for the two sampling periods, the observed significant reduction in ambient PAHs levels of

418 Nanjing was mainly associated with the source change raised by strict and effective PCM.

\subsection{PAHs source apportionment and variations between two periods}

\subsubsection{Diagnostic ratios}

Diagnostic PAHs ratios are a useful tool to distinguish their sources qualitatively (Guillon et al., 2013). Four widely used ratios including Flu/(Flu+Pyr), BaA/(BaA+Chr), Ant/(Ant+Phe) and InP/(InP+BghiP) (Ravindra et al., 2008; Wang et al., 2011; Lin et al., 2015; Li et al., 2016a; Mancilla et al., 2016; Yu et al., 2016) were adopted in Figure 4, with the indicative sources for different values summarized. The values of Flu/(Flu+Pyr) and InP/(InP+BghiP) distributed mainly within 0.5-0.6 and 0.4-0.6, reflecting the marked contributions of coal and biomass burning and petroleum combustion. For $\mathrm{BaA} /(\mathrm{BaA}+\mathrm{Chr})$, the values ranged between $0.11-0.5$, covering the sources of petro genic, coal combustion, vehicle emission, and biomass burning. The values of Ant/(Ant+Phe) (varying in 0.06-0.34) highlighted the importance of wood burning and petroleum. Significant differences were only found for Ant/(Ant+Phe) ratios, decreasing from Period 1 $(0.20 \pm 0.07)$ to Period $2(0.14 \pm 0.05)(\mathrm{P}<0.001)$. However, the ratios of the two periods still indicated the similar sources. It also proposed the cautions that atmospheric reactivity can modify the atmospheric PAHs levels and thus the ratios between PAHs (Ravindra et al., 2008; Mancilla et al., 2016).

\subsubsection{Source apportionment using PMF}

To better explain the variation in PAHs sources of the two periods, the PMF modeling was performed with the source profiles and contributions shown in Figure 5. Oil combustion was associated with the high concentration of the more volatile PAHs such as Fl, Flu, and Pyr, along with moderate levels of the higher molecular weight PAHs, i.e. BbF and InP (Ravindra et al., 2008). Acy, Ace, Fl, Phe, and Ant were typical markers for volatilization of crude oil and petroleum products (Wang et al., 2016b). Therefore, a mixed source of petroleum and oil burning source (PO) was confirmed in this study. PO was also resolved by Chen et al. (2016c), with high loadings on Flu, Pyr and moderate loadings on Pyr, Chr, BeP, BaP, and BghiP. According to the markers listed in section 3.3.3 and the resolved source profiles, totally four sources were identified as coal combustion (CC), PO, wood burning (WB) and vehicle emission (VE), accounting for 
Overall, the PAHs concentrations contributed from the four types of sources all reduced in Period 2, by 83\%, 68\%, 51\% and 33\% for PO, VE, WB, and CC, respectively (Figure 5c). The decreased absolute contributions of them reflected the PCM was effective in reducing PAHs from the sources. Though great efforts have been done by the local government for controlling coal and wood/biomass burning in Nanjing, the long-range transport of the two types of sources from North China partly offset these efforts. It can explain the fewer reduction rates of WB and CC when compared with those for PO and VE. From Table S8, it can be found that in the cities of North China, the contributions of CC were always at a high level, for example, as 38-40\% in Zhengzhou (Wang et al., 2015; Wang et al., 2017b) and 52.1\% in Taiyuan ( $\mathrm{Li}$ et al., 2016a). The contributions of wood/biomass burning at northern Chinese cities ranged in 12\% (Zhengzhou) (Wang et al., 2015)-37.1\% (Xi'an) (Wang et al., 2016b). The contributions of PO as $27 \%$ and $41 \%$ (for marine vessels) were reported for coastal sites in Taiwan (Chen et al., 2016a) and Hong Kong (Ma et al., 2016), respectively. The VE contribution to PAHs in this study was similar to that in Shanghai (43\%) (Liu et al., 2017). Though the PAHs sources differed in various studies, varying with space and time, the PAHs sources in Nanjing exhibited mixture properties, characterized by contributions from local/regional, inland/coastal and southern/northern of China.

Clearly, seasonal variation of the four types of source contributions is illustrated in 468 Period 2) and CC (3.26 \pm 1.49 and $2.81 \pm 1.86 \mathrm{ng} \mathrm{m}^{-3}$ for Period 1 and Period 2) both exhibited 469 highest values in winter, which could be related to the additional fuels combustion for heating purpose. The vehicle emission also contributed most in winter $(9.74 \pm 5.36$ and $3.04 \pm 1.61 \mathrm{ng}$ $471 \mathrm{~m}^{-3}$ for Period 1 and Period 2), implying the enhanced emission at cold start mode. The extreme higher contribution of VE at Spring of Period 1 may be related to the lowest 473 temperature at that period as $8.8 \pm 3.0{ }^{\circ} \mathrm{C}$. For PO emission, it held slightly higher contributions in summer owing to more evaporation under the higher ambient temperature. 
The seasonal variation in source contributions all favored well to the seasonal variation of PAHs

476

477

478

479

480

481

482

483

484

485

486

487

488

489

490

491

492

493

494

495

496

497

498

499

500

501

502

503

504 concentrations as discussed above.

\subsubsection{Source region analysis}

As the results of WPSCF in Figure 7, the source regions with high probabilities of WB were mainly located at the west, northwest and north side of Nanjing and the regions extending to a larger area at Period 2. For CC, the source regions at Period 1 located mainly at the southwest-northeast directions, while they changed to the north and northwest directions at Period 2. The variation in source regions for WB and CC highlighted the importance of the domestic coal and wood burning for heating. For VE, the main source regions were on the southeast side, surrounding Nanjing at Period 1 and then changed to the northwest, north and northeastern of China in Period 2. For PO, the source regions at Period 1 were mainly concentrated in the lower reaches of the Yangtze River and the offshore sea area; while in Period 2, the main source regions moved to the middle reaches of the Yangtze River, the coastal area of PRD and near offshore areas. These regions all hold intensive emissions from both ocean (Fan et al., 2016) and inland vessels/ships (Song, 2015). The geographic origins of the four sources were consistent for weighted concentration weighted trajectory (WCWT) analysis (Figure 8). Higher contributions of WB and CC were found at Period 2 from north China. Lower level contributions of PO and VE at Period 2 were also verified, owing to the shrinkage of the regions with higher WCWT values.

To conclude, after the effective control of air pollutants, the sources of PAHs at Nanjing at Period 2 were mainly influenced by the regional transport of CC and WB from North China especially for domestic use, local+regional transports of ocean and inland vessels/ships and local+regional transports of vehicle emission from North China. It indicated the control of WB, CC and VE should be more strictly in North China. To obtain the local/regional contributions of various sources, a quantitative research is needed based on an accurate emission inventory in the future.

\subsection{Reduced health risks of PAHs and source allocation}

Through the effective source control, the PAHs obviously reduced from Period 1 to Period 2 in Nanjing. It suggested that the human health risks also decreased. By adopting the simple point-estimate approach (Wang et al., 2011), the estimated ILCR for Period 1 and Period 2 were

$4.13 \times 10^{-4}$ and $1.07 \times 10^{-5}$, respectively (Figure 9). Thus, the overall cancer risks due to inhalation 
exposure to PAHs reduced significantly by $61 \%$ for Period $2(p<0.001)$. However, it still exceeded the acceptance limit of cancer risk $\left(10^{-6}\right)$ (Chen et al., 2016a; Lv et al., 2016).

507 Reduced cancer risks were also found for the periods with mega-events, such as the APEC meeting (Xie et al., 2017). It should be noted that uncertainties are inherent in cancer risk assessment, as a lack of knowledge about the factors affecting exposure or toxicity assessment (Hong et al., 2016).

To interpret the risk reduction, contributions of the four types of sources were calculated by PMF model as listed in Figure 10. CC dominated the contributions to ILCR, similar for the two periods, as about 52\%. The contributions to ILCR of PO obviously reduced from $23.5 \%$ to $4.5 \%$ from Period 1 to Period 2; while the contributions of WB and VE increased from $1.75 \%$ to $13.7 \%$ and from $22.3 \%$ to $29.9 \%$. Though still, the dominant sources were coal combustion and vehicle emission, their relative contribution varied in mass concentration and incremental cancer risks. Source pollution controls should not only focus on mass pollution level, but also those having larger toxic and contributing significantly to the health impacts.

Health risks associated with exposure to other pollutants like $\mathrm{CO}, \mathrm{SO}_{2}, \mathrm{NOx}, \mathrm{O}_{3}, \mathrm{PM}_{2.5}$ and associated toxic components (heavy metals, BC, etc.) are interesting and hot topics. The present study only evaluated risks associated with $\mathrm{PM}_{2.5}$-bound PAHs exposure. When taking other pollutants into account, health benefits received from the effective PCMs could be more significant. This is worthy to be investigated in the future, with big datasets (including air pollutants, personal exposure monitoring data, human disease and meteorological parameters) collected and dose-equivalence relationships for different chemicals with health effects clarified.

\section{Conclusion}

As a non-routine monitored pollutants, PAHs were focused in a four-year study in

530 Nanjing to answer whether the air pollution control measures (PCM) can substantially affect 531 the PAHs concentrations, in view of that PAHs can also be impacted by meteorological 532 parameters and atmospheric chemical reaction. Two sampling campaigns in March 2013-January 2014 (Period 1) and November 2015-July 2016 (Period 2) just before and after

534 the local air pollution plan published in April 2014 were completed. 
In Period 2, the average concentrations of $\mathrm{PM}_{2.5}$ significantly reduced by $34 \%$ of that for

Period 1. The total PAHs concentrations exhibited a significantly higher reduction rate as $63 \%$ than $\mathrm{PM}_{2.5}$, indicating the $\mathrm{PCM}$ for $\mathrm{PM}_{2.5}$ have played a positive role in $\mathrm{PAHs}$ reduction unexpectedly. The nonlinear reduction of $\mathrm{PM}_{2.5}$ and associated PAHs was related to their different sources and the different effects of PCM played on $\mathrm{PM}_{2.5}$ and its precursors as well as the different ring of PAHs. The similarity in atmospheric circulation patterns and no obvious differences in meteorological parameters indicated that the main reason for controlling PAHs reduction was the source variation.

Diagnostic ratios and PMF modeling identified four sources, as coal combustion (CC), petroleum and oil burning (PO), wood burning (WB) and vehicle emission (VE). Contributions from all these four source types to ambient PAHs had substantially decreased, from $33 \%$ to $83 \%$.

546 The reduction percentages were more notable for $\mathrm{VE}$ and $\mathrm{PO}$, compared to the reduction percentages in CC and WB. A co-benefit of cancer risk reduction by $61 \%$ was obtained. The cancer risk was still higher than $10^{-6}$, with $\mathrm{CC}$ dominated the contributions as about $52 \%$. In Nanjing, as the dominated contributions of coal burning and vehicle emission to atmospheric PAHs, effective emission mitigation strategies of PAHs should be developed from both local and regional views. Meanwhile, the obvious seasonal variation in PAHs concentrations and source contributions and potential source regions highlighted the importance of further efforts on the reduction of coal and wood burning in North China at a heating period.

This study provides useful data and new insights for assessing the effects of air pollution control measures, from the view of human health, not only just from the reductions of routine air pollutants. The outcomes could be important to regional air quality management and decision makers. The analysis and main findings here are also applicable and helpful for other areas around the world.

\section{Acknowledgements}

561 This study was financially supported by the Key Program of Ministry of Science and Technology 562 of the People's Republic of China (2016YFA0602002; 2017YFC0212602), the Key Program for 563 Environmental Protection in Jiangsu Province (2015017), the National Natural Science 564 Foundation of China $(41301554,41305119)$. The research was also supported by the Fundamental 
565 Research Funds for the Central Universities, China University of Geosciences, Wuhan. We also 566 acknowledge the Qingyue Open Environmental Data Centre. We thank Siyu Yuan, Chunyan Li, 567 and Feng Chen from Jiangsu Academy of Environmental Sciences for the help of field sampling.

568

569 Appendix

570 Materials associated with this manuscript is provided in the supporting file available free of charge

571 via the internet.

572

573 Data are available on request to Shaofei Kong (kongshaofei@ cug.edu.cn).

574

575 Competing interests

576 The authors declare that there is no conflict of interest.

577 


\section{References}

Anastasopoulos, A.T., Wheeler, A.J., Karman, D., Kulka, R.H., 2012. Intraurban concentrations, spatial variability and correlation of ambient polycyclic aromatic hydrocarbons (PAH) and $\mathrm{PM}_{2.5}$. Atmos. Environ. 59, 272-283.

Akyüz, M., Çabuk, H., 2008. Particle-associated polycyclic aromatic hydrocarbons in the atmospheric environment of Zonguldak, Turkey. Sci. Total. Environ. 405, 62-70.

Bae, S., Pan, X.C., Kim, S.Y., Park, K., Kim, Y.H., Kim, H., Hong, Y.C., 2010. Exposures to Particulate Matter and Polycyclic Aromatic Hydrocarbons and Oxidative Stress in Schoolchildren. Environ. Health. Perspect. 118, 579-583.

Bourotte, C., Forti, M.-C., Taniguchi, S., Bícego, M.C., Lotufo, P.A., 2005.A wintertime study of PAHs in fine and coarse aerosols in São Paulo city, Brazil. Atmos. Environ. 39, 3799-3811.

Burstyn, I., Kromhout, H., Partanen, T., Svane, O., Langård, S., Ahrens, W., Kauppinen, T., Stücker, I., Shaham, J., Heederik, D., Ferro, G., Heikkilä, P., Hooiveld, M., Johansen, C., Randem, B.G., Boffetta, P., 2005. Polycyclic aromatic hydrocarbons and fatal ischemic heart disease. Epidemiology 16, 744-750.

Cai, S., Wang, Y., Zhao, B., Wang, S., Chang, X., Hao, J., 2017. The impact of the "Air Pollution Prevention and Control Action Plan" on $\mathrm{PM}_{2.5}$ concentrations in Jing-Jin-Ji region during 2012-2020. Sci. Total. Environ. 580, 197-209.

Callén, M.S., Iturmendi, A., López, J.M., 2014. Source apportionment of atmospheric $\mathrm{PM}_{2.5}$-bound polycyclic aromatic hydrocarbons by a PMF receptor model. Assessment of potential risk for human health. Environ. Pollut. 195, 167-177.

Chen, Y.C., Chiang, H.C., Hsu, C.Y., Yang, T.T., Lin, T.Y., Chen, M.J., Chen, N.T., Wu, Y.S., 2016a. Ambient $\mathrm{PM}_{2.5}$-bound polycyclic aromatic hydrocarbons (PAHs) in Changhua County, central Taiwan: Seasonal variation, source apportionment and cancer risk assessment. Environ. Pollut. 218, 372-382.

Chen, Y., Schleicher, N., Cen, K., Liu, X., Yu, Y., Zibat, V., Dietze, V., Fricker, M., Kaminski, U., Chen, Y., Chai, F., Norra, S., 2016b. Evaluation of impact factors on $\mathrm{PM}_{2.5}$ based on long-term chemical components analyses in the megacity Beijing, China. Chemosphere 155, 234-242. 
Chen, Y., Schleicher, N., Fricker, M., Cen, K., Liu, X., Kaminski, U., Yu, Y., Wu, X., Norra, S., 2016c. Long-term variation of black carbon and $\mathrm{PM}_{2.5}$ in Beijing, China with respect to meteorological conditions and governmental measures. Environ. Pollut. 212, 269-278.

Chen, Y., Li, X., Zhu, T., Han, Y., Lv, D., 2017. $\mathrm{PM}_{2.5}$-bound PAHs in three indoor and one outdoor air in Beijing: Concentration, source and health risk assessment. Sci. Total. Environ. $586,255-264$.

Cheng, Z., Luo, L., Wang, S., Wang, Y., Sharma, S., Shimadera, H., Wang, X., Bressi, M., de Miranda, R.M., Jiang, J., Zhou, W., Fajardo, O., Yan, N., Hao, J., 2016. Status and characteristics of ambient $\mathrm{PM}_{2.5}$ pollution in global megacities. Environ. Int. 89-90, 212-221.

Delfino, R.J., Staimer, N., Tjoa, T., Arhami, M., Polidori, A., Gillen, D. L., George, S. C., Shafer, M. M., Schauer, J. J., Sioutas, C., 2010. Associations of primary and secondary organic aerosols with airway and systemic inflammation in an elderly panel cohort. Epidemiology 21, $892-902$

Donkelaar, D. A., Martin, R.V., Brauer, M., Boys, B.L., 2015. Use of Satellite Observations for Long-Term Exposure Assessment of Global Concentrations of Fine Particulate Matter. Environ. Health. Perspect. 123, 135-143.

Dvorská, A., Lammel, G., Klánová, J., 2011. Use of diagnostic ratios for studying source apportionment and reactivity of ambient polycyclic aromatic hydrocarbons over Central Europe. Atmos. Environ. 45, 420-427.

Edwards, S.C., Jedrychowski, W., Butscher, M., Camann, D., Kieltyka, A., Mroz, E., Flak, E., Li, Z., Wang, S., Rauh, V., Perera, F., 2010. Prenatal Exposure to Airborne Polycyclic Aromatic Hydrocarbons and Children's Intelligence at 5 Years of Age in a Prospective Cohort Study in Poland. Environ. Health. Perspect. 118, 1326-1331.

Fan, Q.Z., Zhang, Y., Ma, W.C., Ma, H.X., Feng, J.L., Yu, Q., Yang, X., Ng, S. K.W., Fu, Q.Y., Chen, L.M., 2016. Spatial and Seasonal Dynamics of Ship Emissions over the Yangtze River Delta and East China Sea and Their Potential Environmental Influence, Environ. Sci. Technol. $50,1322-1329$.

Feng, L., Liao, W., 2016. Legislation, plans, and policies for prevention and control of air pollution in China: achievements, challenges, and improvements. J. Clean. Prod. 112, $1549-1558$. 
Fu, H., Chen, J., 2017. Formation, features and controlling strategies of severe haze-fog pollutions in China. Sci. Total. Environ. 578, 121-138.

Gao, B., Yu, J.Z., Li, S.X., Ding, X., He, Q.F., Wang, X., 2011. Roadside and rooftop measurements of polycyclic aromatic hydrocarbons in $\mathrm{PM}_{2.5}$ in urban Guangzhou: Evaluation of vehicular and regional combustion source contributions. Atmos. Environ. 45, 7184-7191.

Gao, B., Guo, H., Wang, X.M., Zhao, X.Y., Ling, Z.H., Zhang, Z., Liu, T.Y., 2012. Polycyclic aromatic hydrocarbons in $\mathrm{PM}_{2.5}$ in Guangzhou, southern China: Spatiotemporal patterns and emission sources. J. Hazard. Mater. 239-240, 78-87.

Guillon, A., Le Ménach, K., Flaud, P.M., Marchand, N., Budzinski, H., Villenave, E., 2013. Chemical characterization and stable carbon isotopic composition of particulate Polycyclic Aromatic Hydrocarbons issued from combustion of 10 Mediterranean woods. Atmos. Chem. Phys. 13, 2703-2719.

Guo, Z., Lin, T., Zhang, G., Hu, L., Zheng, M., 2009. Occurrence and sources of polycyclic aromatic hydrocarbons and $\mathrm{n}$-alkanes in $\mathrm{PM}_{2.5}$ in the roadside environment of a major city in China. J. Hazard. Mater. 170, 888-894.

Guo, J., He, J., Liu, H., Miao, Y., Liu, H., Zhai, P., 2016. Impact of various emission control schemes on air quality using WRF-Chem during APEC China 2014. Atmos. Environ. 140, $311-319$.

He, J., Fan, S., Meng, Q., Sun, Y., Zhang, J., Zu, F., 2014. Polycyclic aromatic hydrocarbons (PAHs) associated with fine particulate matters in Nanjing, China: Distributions, sources and meteorological influences. Atmos. Environ. 89, 207-215.

Hong, W.J., Jia, H., Ma, W.L., Sinha, R.K., Moon, H.B., Nakata, H., Minh, N.H., Chi, K.H., Li, W.L., Kannan, K., Sverko, E., Li, Y.F., 2016. Distribution, Fate, Inhalation Exposure and Lung Cancer Risk of Atmospheric Polycyclic Aromatic Hydrocarbons in Some Asian Countries. Environ. Sci. Technol. 50, 7163-7174.

Khan, M.F., Latif, M.T., Lim, C.H., Amil, N., Jaafar, S.A., Dominick, D., Mohd Nadzir, M.S., Sahani, M., Tahir, N.M., 2015. Seasonal effect and source apportionment of polycyclic aromatic hydrocarbons in $\mathrm{PM}_{2.5}$. Atmos. Environ. 106, 178-190.

Kim, B. M., Lee, S.B., Kim, J. Y., Kim, S., Seo, J., Bae, G.N., Lee, J. Y., 2016. A multivariate receptor modeling study of air-borne particulate PAHs: Regional contributions in a roadside 
environment. Chemosphere, 144, 1270-1279.

668

669

670

671

672

673

674

675

676

677

678

679

680

681

682

683

684

685

686

687

688

689

690

691

692

693

694

Kong, S.F., 2012. Study on the chemical composition, risk assessment and emission inventory establishment for hazardous components in particulate matter from atmospheric pollution sources. Nankai University. Doctoral Dissertation.

Kong, S., Li, L., Li, X., Yin, Y., Chen, K., Liu, D., Yuan, L., Zhang, Y., Shan, Y., Ji, Y., 2015 a. The impacts of fireworks burning at Chinese Spring Festival on air quality and human health: insights of tracers, source evolution and aging processes. Atmos. Chem. Phys. 15, 2167-2184

Kong, S., Li, X., Li, L., Yin, Y., Chen, K., Yuan, L., Zhang, Y., Shan, Y., Ji, Y., 2015b. Variation of polycyclic aromatic hydrocarbons in atmospheric $\mathrm{PM}_{2.5}$ during winter haze period around 2014 Chinese Spring Festival at Nanjing: Insights of source changes, air mass direction and firework particle injection. Sci. Total. Environ. 520, 59-72.

Kraus, U., Breitner, S., Schnelle-Kreis, J., Cyrys, J., Lanki, T., Rückerl, R., Schneider, A., Brüske, I., Gu, J.W., Devlin, R., Wichmann, H. E., Zimmermann, R., Peters, A., 2011. Particle-associated organic compounds and symptoms in myocardial infarction survivors. Inhal. Toxicol. 23, 431-447.

Li, H., Guo, L., Cao, R., Gao, B., Yan, Y., He, Q., 2016a. A wintertime study of PM $_{2.5}$-bound polycyclic aromatic hydrocarbons in Taiyuan during 2009-2013: Assessment of pollution control strategy in a typical basin region. Atmos. Environ. 140, 404-414.

Li, S.W., Li, H.-B., Luo, J., Li, H.-M., Qian, X., Liu, M.M., Bi, J., Cui, X.Y., Ma, L.Q., $2016 b$. Influence of pollution control on lead inhalation bioaccessibility in $\mathrm{PM}_{2.5}$ : A case study of 2014 Youth Olympic Games in Nanjing. Environ. Int. 94, 69-75.

Li, X., Kong, S., Yin, Y., Li, L., Yuan, L., Li, Q., Xiao, H., Chen, K., 2016c. Polycyclic aromatic hydrocarbons (PAHs) in atmospheric $\mathrm{PM}_{2.5}$ around 2013 Asian Youth Games period in Nanjing. Atmos. Res. 174-175, 85-96.

Lin, Y., Ma, Y., Qiu, X., Li, R., Fang, Y., Wang, J., Zhu, Y., Hu, D., 2015. Sources, transformation, and health implications of PAHs and their nitrated, hydroxylated, and oxygenated derivatives in $\mathrm{PM}_{2.5}$ in Beijing: $\mathrm{PM}_{2.5}$-bound PAHs and the derivatives. J. Geophys. Res. Atmos 120, 7219-7228. 
Liu, G.R., Shi, G.L., Tian, Y.Z., Wang, Y.N., Zhang, C.Y., Feng, Y.C., 2015. Physically constrained source apportionment (PCSA) for polycyclic aromatic hydrocarbon using the Multilinear Engine 2-species ratios (ME2-SR) method. Sci. Total. Environ. 502, 16-21.

Liu, Y., Yan, C., Ding, X., Wang, X., Fu, Q., Zhao, Q., Zhang, Y., Duan, Y., Qiu, X., Zheng, M., 2017. Sources and spatial distribution of particulate polycyclic aromatic hydrocarbons in Shanghai, China. Sci. Total. Environ. 584-585, 307-317.

Lv, Y., Li, X., Xu, T.T., Cheng, T.T., Yang, X., Chen, J.M., Iinuma, Y., Herrmann, H., 2016. Size distributions of polycyclic aromatic hydrocarbons in urban atmosphere: sorption mechanism and source contributions to respiratory deposition. Atmos. Chem. Phys. 16, 2971-2983.

Lupo, P. J., Langlois, P. H., Reefhuis, J., Lawson, C. C., Symanski, E., Desrosiers,T. A., Khodr, Z. G., Agopian, A. J., Waters, M. A., Duwe, K. N., Finnell, R. H., Mitchell, L. E., Moore, C. A., Romitti, P. A., and Shaw, G. M., 2012. Maternal occupational exposure to polycyclic aromatic hydrocarbons: effects on gastroschisis among offspring in the national birth defects prevention study, Environ. Health. Perspect. 120, 910-915.

Ma, Y., Cheng, Y., Qiu, X., Lin, Y., Cao, J., Hu, D., 2016. A quantitative assessment of source contributions to fine particulate matter $\left(\mathrm{PM}_{2.5}\right)$-bound polycyclic aromatic hydrocarbons (PAHs) and their nitrated and hydroxylated derivatives in Hong Kong. Environ. Pollut. 219, $742-749$.

Mancilla, Y., Mendoza, A., Fraser, M.P., Herckes, P., 2016. Organic composition and source apportionment of fine aerosol at Monterrey, Mexico, based on organic markers. Atmos. Chem. Phys. 16, 953-970.

Marchand, N., Besombes, J.L., Chevron, N., Masclet, P., Aymoz, G., Jaffrezo, J.L., 2004. Polycyclic aromatic hydrocarbons (PAHs) in the atmospheres of two French alpine valleys: sources and temporal patterns. Atmos. Chem. Phys. 4, 1167-1181.

Martellini, T., Giannoni, M., Lepri, L., Katsoyiannis, A., Cincinelli, A., 2012. One year intensive $\mathrm{PM}_{2.5}$ bound polycyclic aromatic hydrocarbons monitoring in the area of Tuscany, Italy. Concentrations, source understanding and implications. Environ. Pollut. 164, 252-258.

Pereira, G. M., Teinilä, K., Custódio, D., Gomes Santos, A., Xian, H., Hillamo, R., Alves, C.A., Bittencourt de Andrade, J., Olímpio da Rocha, G., Kumar, P., Balasubramanian, R., de Fátima Andrade, M., de Castro Vasconcellos, P., 2017. Airborne particles in the Brazilian 
city of São Paulo: One-year investigation for the chemical composition and source apportionment. Atmos. Chem. Phys. 17, 11943-11969

Pinxteren, D., Brüggemann, E., Gnauk, T., Iinuma, Y., Müller, K., Nowak, A., Achtert, P., Wiedensohler, A., Herrmann, H., 2009. Size- and time-resolved chemical particle characterization during CAREBeijing-2006: Different pollution regimes and diurnal profiles. J. Geophys. Res. Atmos. 114, 899-912.

Perera, F.P., Tang, D., Wang, S., Vishnevetsky, J., Zhang, B., Diaz, D., Camann, D., Rauh, V., 2012. Prenatal Polycyclic Aromatic Hydrocarbon (PAH) Exposure and Child Behavior at Age 6-7 Years. Environ. Health. Perspect. 120, 921-926.

Ravindra, K., Sokhi, R., Vangrieken, R., 2008. Atmospheric polycyclic aromatic hydrocarbons: Source attribution, emission factors and regulation. Atmos. Environ. 42, 2895-2921.

Saffari, A., Daher, N., Samara, C., Voutsa, D., Kouras, A., Manoli, E., Karagkiozidou, O., Vlachokostas, C., Moussiopoulos, N., Shafer, M.M., Schauer, J.J., Sioutas, C., 2013. Increased biomass burning due to the economic crisis in Greece and its adverse impact on wintertime air quality in Thessaloniki. Environ. Sci. Technol. 47, 13313-13320.

Scinicariello, F., Buser, M.C., 2014. Urinary Polycyclic Aromatic Hydrocarbons and Childhood Obesity: NHANES (2001-2006). Environ. Health. Perspect. 122, 299-303.

Shen, G., Chen, Y., Wei, S., Fu, X., Ding, A., Wu, H., Tao, S., 2014. Can Coronene and/or Benzo(a)pyrene/Coronene ratio act as unique markers for vehicle emission? Environ. Pollut. $184,650-653$.

Shi, G.L., Liu, G.R., Tian, Y.Z., Zhou, X.Y., Peng, X., Feng, Y.C., 2014. Chemical characteristic and toxicity assessment of particle associated PAHs for the short-term anthropogenic activity event: During the Chinese New Year's Festival in 2013. Sci. Total. Environ. 482-483, 8-14.

Shrivastava, M., Lou, S., Zelenyuk, A., Easter, R.C., Corley, R.A., Thrall, B.D., Rasch, P.J., Fast, J.D., Massey Simonich, S.L., Shen, H., Tao, S., 2017. Global long-range transport and lung cancer risk from polycyclic aromatic hydrocarbons shielded by coatings of organic aerosol. Proc. Natl. Acad. Sci. 114, 1246-1251.

Song, Y., 2015. Research of emission inventory and emission character of inland and offshore ships, Master thesis, Beijing Institute of Technology, China, 1-94 (in Chinese). 
Teixeira, E.C., Agudelo-Castañeda, D.M., Mattiuzi, C.D.P., 2015. Contribution of polycyclic aromatic hydrocarbon (PAH) sources to the urban environment: A comparison of receptor models. Sci. Total. Environ. 538, 212-219.

Thornhill, D.A., de Foy, B., Herndon, S.C., Onasch, T.B., Wood, E.C., Zavala, M., Molina, L.T., Gaffney, J.S., Marley, N.A., Marr, L.C., 2008. Spatial and temporal variability of particulate polycyclic aromatic hydrocarbons in Mexico City. Atmos. Chem. Phys. 8, 3093-3105.

Wang, G., Huang, L., Xin Zhao, Niu, H., Dai, Z., 2006a. Aliphatic and polycyclic aromatic hydrocarbons of atmospheric aerosols in five locations of Nanjing urban area, China. Atmos. Res. 81, 54-66.

Wang, G., Kawamura, K., Lee, S., Ho, K., Cao, J., 2006b. Molecular, Seasonal, and Spatial Distributions of Organic Aerosols from Fourteen Chinese Cities. Environ. Sci. Technol. 40, $4619-4625$.

Wang, G., Kawamura, K., Zhao, X., Li, Q., Dai, Z., Niu, H., 2007. Identification, abundance and seasonal variation of anthropogenic organic aerosols from a mega-city in China. Atmos. Environ. 41, 407-416.

Wang, X., Cheng, H., Xu, X., Zhuang, G., Zhao, C., 2008. A wintertime study of polycyclic aromatic hydrocarbons in $\mathrm{PM}_{2.5}$ and $\mathrm{PM}_{2.5-10}$ in Beijing: Assessment of energy structure conversion. J. Hazard. Mater. 157, 47-56.

Wang, W., Jariyasopit, N., Schrlau, J., Jia, Y., Tao, S., Yu, T.W., Dashwood, R.H., Zhang, W., Wang, X., Simonich, S.L.M., 2011. Concentration and Photochemistry of PAHs, NPAHs, and OPAHs and Toxicity of $\mathrm{PM}_{2.5}$ during the Beijing Olympic Games. Environ. Sci. Technol. 45, 6887-6895.

Wang, J., Li, X., Jiang, N., Zhang, W., Zhang, R., Tang, X., 2015. Long term observations of $\mathrm{PM}_{2.5}$-associated PAHs: Comparisons between normal and episode days. Atmos. Environ. $104,228-236$.

Wang, J., Hang Ho, S.S., Huang, R., Gao, M., Liu, S., Zhao, S., Cao, J., Wang, G., Shen, Z., Han, Y., 2016a. Characterization of parent and oxygenated-polycyclic aromatic hydrocarbons (PAHs) in Xi'an, China during heating period: An investigation of spatial distribution and transformation. Chemosphere 159, 367-377. 
Wang, Q., Liu, M., Yu, Y., Li, Y., 2016b. Characterization and source apportionment of $\mathrm{PM}_{2.5}$-bound polycyclic aromatic hydrocarbons from Shanghai city, China. Environ. Pollut. $218,118-128$.

Wang, J., Zhao, B., Wang, S., Yang, F., Xing, J., Morawska, L., Ding, A., Kulmala, M., Kerminen, V.M., Kujansuu, J., Wang, Z., Ding, D., Zhang, X., Wang, H., Tian, M., Petäjä, T., Jiang, J., Hao, J., 2017a. Particulate matter pollution over China and the effects of control policies. Sci. Total. Environ. 584-585, 426-447.

Wang, Q., Jiang, N., Yin, S., Li, X., Yu, F., Guo, Y., Zhang, R., 2017b. Carbonaceous species in $\mathrm{PM}_{2.5}$ and $\mathrm{PM}_{10}$ in urban area of Zhengzhou in China: Seasonal variations and source apportionment. Atmos. Res. 191, 1-11.

Wang, Y., Xue, Y., Tian, H., Gao, J., Chen, Y., Zhu, C., Liu, H., Wang, K., Hua, S., Liu, S., Shao, P., 2017c. Effectiveness of temporary control measures for lowering $\mathrm{PM}_{2.5}$ pollution in Beijing and the implications. Atmos. Environ. 157, 75-83.

Wang, G., Cheng, S., Wei, W., Yang, X., Wang, X., Jia, J., Lang, J., Lv, Z., 2017d. Characteristics and emission-reduction measures evaluation of $\mathrm{PM}_{2.5}$ during the two major events: APEC and Parade. Sci. Total. Environ. 595, 81-92.

Wingfors, H., Hägglund, L., Magnusson, R., 2011. Characterization of the size-distribution of aerosols and particle-bound content of oxygenated PAHs, PAHs, and n-alkanes in urban environments in Afghanistan. Atmos. Environ. 45, 4360-4369.

Xie, Y., Zhao, B., Zhao, Y., Luo, Q., Wang, S., Zhao, B., Bai, S., 2017. Reduction in population exposure to $\mathrm{PM}_{2.5}$ and cancer risk due to $\mathrm{PM}_{2.5}$-bound PAHs exposure in Beijing, China during the APEC meeting. Environ. Pollut. 225, 338-345.

Xu, H.M., Tao, J., Ho, S.S.H., Ho, K.F., Cao, J.J., Li, N., Chow, J.C., Wang, G.H., Han, Y.M., Zhang, R.J., Watson, J.G., Zhang, J.Q., 2013. Characteristics of fine particulate non-polar organic compounds in Guangzhou during the 16th Asian Games: Effectiveness of air pollution controls. Atmos. Environ. 76, 94-101.

Xu, J., Chang, L., Qu, Y., Yan, F., Wang, F., Fu, Q., 2016a. The meteorological modulation on $\mathrm{PM}_{2.5}$ interannual oscillation during 2013 to 2015 in Shanghai, China. Sci. Total. Environ. $572,1138-1149$. 
Xu, H., Ho, S.S.H., Gao, M., Cao, J., Guinot, B., Ho, K.F., Long, X., Wang, J., Shen, Z., Liu, S., Zheng, C., Zhang, Q., 2016b. Microscale spatial distribution and health assessment of $\mathrm{PM}_{2.5}$-bound polycyclic aromatic hydrocarbons (PAHs) at nine communities in Xi'an, China. Environ. Pollut. 218, 1065-1073.

Yan, B., Zheng, M., Hu, Y., Ding, X., Sullivan, A.P., Weber, R.J., Baek, J., Edgerton, E.S., Russell, A.G., 2009. Roadside, Urban, and Rural Comparison of Primary and Secondary Organic Molecular Markers in Ambient PM2.5. Environ. Sci. Technol. 43, 4287-4293.

Yang, H., Yu, J.Z., Ho, S.S.H., Xu, J., Wu, W.S., Wan, C.H., Wang, X., Wang, X., Wang, L., 2005. The chemical composition of inorganic and carbonaceous materials in $\mathrm{PM}_{2.5}$ in Nanjing, China. Atmos. Environ. 39, 3735-3749.

Ye, Z., Liu, J., Gu, A., Feng, F., Liu, Y., Bi, C., Xu, J., Li, L., Chen, H., Chen, Y., Dai, L., Zhou, Q., Ge, X., 2017. Chemical characterization of fine particulate matter in Changzhou, China, and source apportionment with offline aerosol mass spectrometry. Atmos. Chem. Phys. 17, 2573-2592.

Yu, Q., Gao, B., Li, G., Zhang, Y., He, Q., Deng, W., Huang, Z., Ding, X., Hu, Q., Huang, Z., Wang, Y., Bi, X., Wang, X., 2016. Attributing risk burden of $\mathrm{PM}_{2.5}$-bound polycyclic aromatic hydrocarbons to major emission sources: Case study in Guangzhou, south China. Atmos. Environ. 142, 313-323.

Zhang, Y., Tao, S., 2009. Global atmospheric emission inventory of polycyclic aromatic hydrocarbons (PAHs) for 2004. Atmos. Environ. 43, 812-819.

Zhou, Y., Xing, X.F., Lang, J.L., Chen, D.S., Cheng, S.Y., Wei, L., Wei, X., Liu, C., 2017. A comprehensive biomass burning emission inventory with high spatial and temporal resolution in China, Atmos. Chem. Phys. 17, 2839-2864.

Zhu, Y., Yang, L., Meng, C., Yuan, Q., Yan, C., Dong, C., Sui, X., Yao, L., Yang, F., Lu, Y., Wang, W., 2015. Indoor/outdoor relationships and diurnal/nocturnal variations in water-soluble ion and PAH concentrations in the atmospheric $\mathrm{PM}_{2.5}$ of a business office area in Jinan, a heavily polluted city in China. Atmos. Res. 153, 276-285. 